\title{
Risk Analysis and Portfolio Modelling
}

\author{
David Edmund Allen $1,2,3, * \mathbb{1}$ and Elisa Luciano ${ }^{4}$ \\ 1 School of Mathematics and Statistics, University of Sydney, Sydney, NSW 2006, Australia \\ 2 Department of Finance, Asia University, Wufeng 41354, Taiwan \\ 3 School of Business and Law, Edith Cowan University, Joondalup, WA 6027, Australia \\ 4 Department of Economics and Statistics, University of Torino, I-10134 Torino, Italy; elisa.luciano@unito.it \\ * Correspondence: profallen2007@gmail.com
}

Received: 18 September 2019; Accepted: 18 September 2019; Published: 21 September 2019

\begin{abstract}
Financial risk measurement is a challenging task because both the types of risk and their measurement techniques evolve quickly. This book collects a number of novel contributions for the measurement of financial risk, which addresses partially explored risks or risk takers in a wide variety of empirical contexts.
\end{abstract}

Keywords: risk analysis; portfolio analysis; risk attribution

In a special issue of the Journal of Risk and Financial Management, there was a call for contributions within the broad topic of portfolio analysis. This topic includes any novel, theoretical, or empirical research application in the area of portfolio analysis. This book collects a number of novel contributions for the measurement of financial risk, which address partially explored risks or risk takers in a wide variety of empirical contexts. Financial risk measurement is a challenging task because both the types of risk and their measurement techniques evolve quickly.

The more theoretical contributions in the book include an adjusted present value (APV) model of capital allocation for decentralized businesses. Further, it includes an integration of communication regarding theoretic models and portfolio theory. At the opposite end of the spectrum, this collection includes a study that details the links between insider trading and institutional holdings in the context of United States (US) equity issues (SEOs).

A number of issues relating to portfolio risk and performance are addressed in this volume. Apart from the construction of novel portfolio performance benchmarks, these include various aspects of default rates, probability of loss, and loss distributions on small enterprise loans. Further, value-at-risk (VaR) is examined in the context of crop insurance programs, as is herding in smart beta investments and determinants of sovereign risk premiums. There are two contributions regarding real estate markets that include the analysis of links between real estate and stock markets, plus the analysis of risk in Sweden housing market segments.

Turnbull (2018) considers a theory of capital allocation for decentralized businesses, considering the costs associated with risk capital. He derives an APV expression for making investment decisions that incorporates a time varying profile of risk capital. This differs from a top-down approach, in which, in the case of a bank, senior management decides on the optimal buffer size and the allocation to individual businesses within the bank make up its component activities. Managers who run sub-units of said business would presumably prefer a situation where the determination of a project's risk capital depended on project characteristics under their remit, not the characteristics of the bank as a whole. This is because they are concerned about risks over which they have some control. Turnbull derives an expression for the APV of a business by aggregating across the individual projects within a business. The associated difficulty is that this means there is no simple benchmark, such as risk adjusted rate of 
return on capital (RAROC), with which to compare the relative performance of different projects in the same company.

Using U.S. data, Wu and Yang (2018) analyze the impact of insider trades and institutional holdings on seasoned equity offerings (SEOs). They report that insider transactions have a significant impact on institutional holdings in SEOs. They suggest that institutional holdings change in the same direction as insider transactions. They interpret this as evidence that both insiders and institutional investors have similar SEO information sources. They also report a link between insider transactions and the long-term performance of SEO firms, which have greater explanatory power than institutional holdings.

Frahm and Huber (2019) propose a new performance measure that can be used to compare a strategy with a specified benchmark and develop the basic statistical properties of its maximum likelihood estimator in a Brownian motion framework. They adopt outperformance probability as a measure of portfolio performance and investigate whether mutual funds are able to beat the S\&P 500 or the Russell 1000. They report that most mutual funds are able to beat the market, but not at standard levels of significance. Further, Frahm and Huber suggest that a performance metric should refer to differential returns when comparing a strategy with a given benchmark and should not compare both the strategy and the benchmark with a money market account. This is a standard feature of asset pricing-based performance metrics, which are linear and include the return on a risk-free asset. The authors suggest that this explains why mutual funds often appear to underperform in the market. This conclusion, they assert, is fallacious.

The best known performance measure is the Sharpe ratio, which divides the expected excess return on investment by the standard deviation of the excess return. Most other performance measures found in the literature are based on the same principle - they divide the return on investment by its risk, where the precise meaning of "return" and "risk" differ from one performance measure to another. Indeed, asset pricing is currently in a state of confusion. Cochrane (2011) complained about a "zoo" of factors that compete to explain risk-return relationships. Each different factor model will produce a different performance metric.

Frahm and Huber term the new metric the outperformance probability (OP), a concept which differs from customary return-to-risk measures. Their metric compares some strategies with a specified benchmark, which do not necessarily need to include a money market account. Their measure is based on a probability and is not determined in terms of specific holding periods. Furthermore, the holding period of the investor is consider to be random. This enabled them to compute the performance of an investment opportunity for arbitrary liquidity preferences.

Bedin et al. (2019) investigate the default probability, recovery rates, and loss distribution of a portfolio of securitized loans granted to Italian small and medium enterprises (SMEs). The authors use loan level data information provided by the European DataWarehouse platform, employing a logistic regression to estimate the company default probability. The analysis includes loan-level default probabilities and recovery rates used to estimate the loss distribution of the underlying assets. They report that bank securitized loans are less risky than an average bank lending to small and medium enterprises. This analysis provides novel information about the risks of asset backed securities (ABS) when structured in portfolios featuring loans to small to medium enterprises (SMEs).

Ramsey and Goodwin (2019) consider VaR and models of dependence in the U.S. Federal Crop Insurance Program. This is a complex issue because the program consists of policies across a wide range of crops, plans, and locations. Outcomes are affected by weather and other latent variables such as pests. This creates a complex dependency structure. The computation of $\mathrm{VaR}$ is an important issue because a standard reinsurance agreement (SRA) allows a portion of the risk to be transferred to the federal government. VaR is typically expressed as a probable maximum loss (PML) or as a return in the form of a loss in a given period.

Ramsey and Goodwin (2019) estimate the VaR of a hypothetical portfolio of crop insurance policies in which the marginal distributions are permitted to follow an arbitrary distribution. Given that any joint distribution can be decomposed into a marginal distribution and a copula function, they apply 
bounds to the VaR via the rearrangement algorithm (Embrechts et al. 2013). They report that there is a large degree of model risk related to the assumed dependence structure.

Krkoska and Schenk-Hoppé (2019) analyze herding in smart beta investment products and posit that the herding of investors is a major risk factor typically ignored in statistical approaches to portfolio modelling and risk management. Smart beta investment products involve the application of factor models, such as the ubiquitous Fama-French three-factor model, as an investment screening tool. The authors review the literature and suggest potential analytical approaches.

Mpapalika and Malikane (2019) examine the determinants of sovereign risk premiums in African countries using a fixed effects panel data approach. They report that public debt to GDP ratio, GDP growth, inflation rate, foreign exchange reserves, commodity price, and market sentiment are significant determinants at $5 \%$ and $10 \%$ levels. A feature of their sample is that a country's risk premium is an important factor in determining the choice between foreign currency borrowing and local currency borrowing. The stability of macroeconomic factors plays an important role in influencing the sovereign risk premium.

Liow et al. (2019) applies a wavelet analysis to explore the relationship between securitized real estate and local stock markets across five developed markets. The advantage of wavelet analysis is that it facilitates the decomposition of a time series into components of different frequency or duration. A standard time series analysis has a constant interval in finance applications, as exemplified by daily, weekly, or monthly data. Their approach permits the analysis of correlations at different frequencies. The authors report that securitized real estate markets appear to lead stock markets in the short-term, whereas stock markets tend to lead securitized real estate markets in the long-term, and to a lesser degree in the medium-term.

Arici et al. (2019) propose a communication theoretic interpretation of modern portfolio theory that includes short sales, leverage, and transaction costs. Thus, their paper posits a connection between portfolio optimization and matched filter theory, providing a means of incorporating the aforementioned market features.

Using the owner-occupied apartment market segment of the Swedish market in Stockholm, Wilhelmsson and Zhao (2018) analyze the risks from housing apartments in different housing market segments. They analyze risk in this market from the lender's perspective, focusing on credit risk and market risk; they suggest that both can be reduced by diversification. They analyze diversification across a number of criteria, including geographical dispersion and ownership characteristics, using a variety of methods including beta analysis, hedonic pricing, and analytical hierarchy processing. Their results suggest that both larger apartments and more recently built apartments experience higher price volatility. They suggest that older apartments with just one room are more likely to experience risk reduction benefits in the context of a housing portfolio.

Sajjad and Zakaria (2018) examine the relationship between credit rating scales and debt maturity choices using a sample of non-financial listed Asian companies rated by Standard and Poor's rating agency. The non-financial companies are chosen from eight selected Asian regions: Japan, South Korea, Singapore, China, Hong Kong, Indonesia, Malaysia, and India. Moreover, Sajjad and Zakaria apply a generalized linear model (GLM) and pool an ordinary least square (OLS) in their analysis. Their results suggest that companies with high and low ratings have a shorter debt maturity whilst companies with medium ratings have a longer debt maturity structure. There is a negative association between liquidity and longer debt maturity structures.

This volume includes a wide variety of theoretical and empirical contributions that address a wide range of issues and topics related to risk analysis, portfolio analysis, and risk attribution.

Funding: Financial support from the Italian ministry of Education, University and Research (MIUR), Dipartimenti di eccellenza, grant 2018-2022, is gratefully ackowledged.

Conflicts of Interest: The authors declare no conflict of interest. 


\section{References}

Arici, Giorgio, Marco Dalai, Riccardo Leonardi, and Arnaldo Spalvieri. 2019. A Communication Theoretic Interpretation of Modern Portfolio Theory Including Short Sales, Leverage and Transaction Costs. Journal of Risk and Financial Management 12: 4. [CrossRef]

Bedin, Andrea, Monica Billio, Michele Costola, and Loriana Pelizzon. 2019. Credit Scoring in SME Asset-Backed Securities: An Italian Case Study. Journal of Risk and Financial Management 12: 89. [CrossRef]

Cochrane, John H. 2011. Presidential address: Discount rates. The Journal of Finance 66: 1047-108. [CrossRef]

Embrechts, Paul, Puccetti Giovanni, and Rüschendorf Ludger. 2013. Model uncertainty and VaR aggregation. Journal of Banking and Finance 37: 2750-64. [CrossRef]

Frahm, Gabriel, and Ferdinand Huber. 2019. The Outperformance Probability of Mutual Funds. Journal of Risk and Financial Management 12: 108. [CrossRef]

Krkoska, Eduard, and Klaus R. Schenk-Hoppé. 2019. Herding in Smart-Beta Investment Products. Journal of Risk and Financial Management 12: 47. [CrossRef]

Liow, Kim H., Xiaoxia Zhou, Qiang Li, and Yuting Huang. 2019. Time-Scale Relationship between Securitized Real Estate and Local Stock Markets: Some Wavelet Evidence. Journal of Risk and Financial Management 12: 16. [CrossRef]

Mpapalika, Jane, and Christopher Malikane. 2019. The Determinants of Sovereign Risk Premium in African Countries. Journal of Risk and Financial Management 12: 29. [CrossRef]

Ramsey, A. Ford, and Barry K. Goodwin. 2019. Value-at-Risk and Models of Dependence in the U.S. Federal Crop Insurance Program. Journal of Risk and Financial Management 12: 65. [CrossRef]

Sajjad, Faiza, and Muhammad Zakaria. 2018. Credit Ratings and Liquidity Risk for the Optimization of Debt Maturity Structure. Journal of Risk and Financial Management 11: 24. [CrossRef]

Turnbull, Stuart M. 2018. Capital Allocation in Decentralized Businesses. Journal of Risk and Financial Management 11: 82. [CrossRef]

Wilhelmsson, Mats, and Jianyu Zhao. 2018. Risk Assessment of Housing Market Segments: The Lender's Perspective. Journal of Risk and Financial Management 11: 69. [CrossRef]

Wu, Ching-Chih, and Tung-Hsiao Yang. 2018. Insider Trading and Institutional Holdings in Seasoned Equity Offerings. Journal of Risk and Financial Management 11: 53. [CrossRef] 